УДК 378.6.126:796.011.3

DOI 10.23951/2307-6127-2020-1-154-161

\title{
ФОРМИРОВАНИЕ ЗНАНИЙ У СТУДЕНТОВ ФАКУЛЬТЕТОВ ФИЗИЧЕСКОЙ КУЛЬТУРЫ И СПОРТА ПО ПОСТРОЕНИЮ ВОССТАНОВИТЕЛЬНЫХ МИКРОЦИКЛОВ В СОРЕВНОВАТЕЛЬНОМ ПЕРИОДЕ ТРЕНИРОВОЧНОГО МАКРОЦИКЛА
}

\author{
В. Ф. Пешков, А. В. Григорян
}

\section{Томский государственный педагогический университет, Томск}

\begin{abstract}
Представлены обоснование, разработка и результаты апробации учебного материала по теме «Планирование восстановительных средств в спорте» для учебных дисциплин восстановительно-профилактической направленности и дисциплин по единоборствам, преподаваемых в университетах и на факультетах физической культуры и спорта. Обоснование содержания учебной темы опирается на научно-методические подходы к планированию восстановительных средств в спорте, на теории и методики восстановительно-профилактических средств, теории и методики спортивной тренировки. Разработан вариант планирования восстановительных микроциклов в структуре соревновательного периода боксеров, тренирующихся на этапе спортивной специализации. Определено место восстановительных микроциклов в структуре соревновательного мезоцикла соревновательного периода у боксеров, процентное соотношение объема общей физической и специальной физической подготовки, технической подготовки и объема применения комплекса педагогических, медико-биологических и психологических средств восстановления для каждого из запланированных восстановительных микроциклов. Представлено соотношение применения педагогических, медико-биологических и психологических средств восстановления в трех запланированных восстановительных микроциклах. Экспериментально доказана эффективность разработанного варианта планирования.
\end{abstract}

Ключевые слова: профессиональная подготовка, соревновательный микроиикл, соревновательный период, восстановительные микроцикль, восстановительные средства.

На факультетах физической культуры и спорта государственных педагогических университетов преподаются учебные дисциплины восстановительно-профилактической и спортивной направленности, такие как «Восстановительные средства в спорте», «Теория и методика видов единоборств» $[1,2]$. Важной учебной темой данных дисциплин является тема «Планирование восстановительно-профилактических средств в спорте». Разработаны научно-методические основы планирования восстановительно-профилактических средств в спорте [3]. Однако недостаточно научно обосновано и разработано планирование восстановительно-профилактических средств для конкретных видов спорта, в частности для бок$\mathrm{ca}$, с учетом специфики построения и решения задач в этапах годичного цикла, общеподготовительного и специально подготовительного этапов подготовительного периода, в мезоциклах и микроциклах соревновательного, подготовительного и переходного периодов. Требует своего решения проблема планирования восстановительных микроциклов в соревновательном мезоцикле соревновательного периода боксеров, тренирующихся на этапе спортивной специализации.

В современной системе спортивной подготовки применение восстановительных средств рассматривается как важная часть подготовки спортсменов [1-10]. 
Высокий уровень современных тренировочных и соревновательных нагрузок требует более широкого и целенаправленного применения различных восстановительных средств в подготовке боксеров. Особое значение это имеет при подготовке боксеров в соревновательном периоде. Именно в соревновательном периоде проверяется уровень спортивной подготовленности боксера, эффективность методики подготовки к соревнованиям. Этот период характеризуется состоянием большого физического и психоэмоционального утомления [11-13].

Высокие по объему и интенсивности тренировочные нагрузки нередко приводят к различным повреждениям и заболеваниям, невыполнению планов спортивной подготовки. Поэтому возникает необходимость предупреждения повреждений и заболеваний опорнодвигательного аппарата, снятия утомления и психического перенапряжения [1-10]. Процесс применения средств восстановления рассматривается как восстановительно-профилактическая сторона подготовки в структуре спортивной подготовки [4].

Анализ литературы и практики показал, что научно-методические подходы к применению средств восстановления у боксеров не соответствуют современным требованиям практики и науки. Выполнение больших тренировочных и соревновательных нагрузок в соревновательном периоде у боксеров, тренирующихся на этапе спортивной специализации, а также изменения в правилах соревнований требуют обоснования планирования восстановительных микроциклов в системе подготовки боксеров.

Цель исследования - на основе теоретического и эмпирического анализа обосновать и разработать эффективное планирование восстановительных микроциклов в структуре соревновательного мезоцикла соревновательного периода у боксеров, тренирующихся на этапе спортивной специализации.

База исследования: студенты-боксеры, тренирующиеся на этапе спортивной специализации, в количестве 24 человек. Были подобраны две группы, экспериментальная и контрольная (по 12 человек в каждой), однородные по квалификации, уровню проявления специальных физических качеств.

Подбор восстановительных средств, их планирование в годичном цикле, удельный вес того или иного из них, их сочетание, дозировка, продолжительность использования обусловлены конкретным состоянием спортсмена, его здоровьем, уровнем тренированности, индивидуальной способностью к восстановлению, видом спорта, этапом и используемой методикой тренировки, характером проведенной и предстоящей тренировочной работы, режимом спортсмена, фазой восстановления [4-10].

Современное представление о планировании годичных циклов подготовки связано с ее определенной структурой, в которой выделяют: микроциклы, мезоциклы и макроциклы. Под микроциклом тренировки понимается совокупность нескольких тренировочных занятий, которые вместе с днями отдыха составляют относительно законченный тренировочный процесс. Длительность микроцикла составляет 7-14 дней. В различных видах спорта выделяют от четырех до девяти различных типов микроциклов: втягивающий, базовый (общеподготовительный), контрольно-подготовительный (модельный и специально-подготовительный), подводящий, восстановительный и соревновательный. Мезоцикл - это структура средних циклов тренировки, включающих относительно законченный по воздействию ряд микроциклов. Выделяют следующие мезоциклы: втягивающие, базовые, контрольно-подготовительные, предсоревновательные, соревновательные, восстановительные. Мезоциклы включают от двух до шести микроциклов. Годичный цикл состоит из трех периодов: подготовительного, соревновательного и переходного. Планирование восстановительных средств определяется решением конкретных задач в микроциклах, мезоциклах периодов годичного цикла $[3,10]$. 
Основная задача подготовительного периода - повышение уровня общей и специальной физической подготовленности боксеров, изучение и совершенствование новых сложных технических элементов. На этом этапе повышаются объемы и интенсивность тренировочных нагрузок, направленных на совершенствование физической подготовленности. Основными задачами соревновательного периода на этапе спортивной специализации являются повышение достигнутого уровня специальной подготовленности и достижение высоких спортивных результатов в соревнованиях. Эти задачи решаются с помощью соревновательных и специальных подготовительных упражнений. Основными задачами переходного периода на этапе спортивной специализации являются обеспечение полноценного отдыха после тренировочных, соревновательных нагрузок прошедшего макроцикла, а также поддержание определенного уровня тренированности для обеспечения оптимальной готовности спортсмена к началу очередного макроцикла. Особое внимание обращается на полноценное физическое и особенно психическое восстановление боксеров.

Каждый период очередного годичного цикла должен начинаться и завершаться на более высоком уровне тренировочных нагрузок по сравнению с соответствующими периодами предыдущего годичного цикла [10]. Это в значительной степени обеспечивается за счет эффективно спланированных восстановительных микроциклов [3]. Традиционно в боксе восстановительные микроциклы планируются в течение и в конце подготовительного периода, а в соревновательном периоде - в конце соревновательного мезоцикла.

По нашему мнению, на основе учета специфики соревновательной деятельности боксеров необходимо найти место для восстановительных микроциклов в соревновательном мезоцикле соревновательного периода, их оптимальное количество и длительность, определить их содержание, что обеспечит уменьшение психического и физического утомления, развитие и сохранение потенциала спортивной подготовленности. При этом мы считаем, что длительность восстановительного микроцикла в соревновательном макроцикле соревновательного периода должна составлять три-четыре дня, а не пять-семь дней, как принято в практике.

В боксе соревновательный период годичного цикла подготовки боксеров на этапе спортивной специализации включает три мезоцикла: контрольно-подготовительный, предсоревновательный и соревновательный. Соревновательный мезоцикл включает в себя базовый, контрольно-подготовительный, ударный, предсоревновательный, соревновательный и восстановительный микроциклы.

Мы на основе анализа данных о структуре, величинах нагрузок в мезоциклах соревновательного периода о динамике специальной работоспособности, функциональных показателях, оценивающих состояние сердечно-сосудистой системы, полученных в результате предварительных исследований в предыдущих соревновательных мезоциклах соревновательного периода, включили в соревновательный мезоцикл соревновательного периода годичного цикла подготовки боксеров, тренирующихся на этапе спортивной специализации, три восстановительных микроцикла в следующей последовательности: базовый - ударный - восстановительный; контрольно-подготовительный - предсоревновательный - восстановительный; соревновательный - восстановительный.

В первом восстановительном микроцикле, который включен после базового и ударного микроциклов, было запланировано и реализовано сочетание средств общей физической подготовки, характерной для бокса, и специальной физической подготовки в комплексе с технической подготовкой в равном соотношении и комплекс педагогических, медико-биологических и психологических средств в процентном соотношении преимущественно медико-биологического характера для устранения локального и общего физического утомле- 
Пешков В. Ф., Григорян А. В. Формирование знаний у студентов факультетов физической культурыл..

ния. Процентное соотношение общей физической подготовки - специальной физической подготовки в комплексе с технической подготовкой - всего комплекса восстановительных средств следующее: 30-30-40 \%; соотношение педагогических, медико-биологических и психологических средств восстановления составило 20-50-30 \%.

Во втором восстановительном микроцикле, запланированном после контрольно-подготовительного и предсоревновательного микроциклов перед соревновательным микроциклом, было запланировано и реализовано сочетание средств специальной физической подготовки в комплекс с технической подготовкой и комплекса педагогических, медико-биологических и психологических восстановительных средств в следующем процентном соотношении: 40-60 \%. При этом соотношение педагогических, медико-биологических и психологических средств 20-30-50\%.

В третий восстановительный микроцикл, запланированный и проведенный после соревновательного микроцикла, были включены средства общей физической подготовки, неспецифические для бокса, и комплекс педагогических, медико-биологических и психологических средств в соотношении: 40-60 \%. В структуре восстановительных средств применялось следующее процентное соотношение педагогических, медико-биологических и психологических средств: 30-40-30\%.

В табл. 1 представлено распределение объема и интенсивности нагрузки по микроциклам соревновательного мезоцикла соревновательного периода годичного цикла подготовки боксеров, тренирующихся на этапе спортивной специализации.

Таблица 1

Параметры нагрузки в микрочиклах соревновательного мезоцикла соревновательного периода годичного циикла подготовки боксеров, тренирующихся на этапе спортивной специиализации

\begin{tabular}{|c|c|c|c|}
\hline Тип микроцикла & Занятия микроцикла & Объем нагрузки, \% & Интенсивность нагрузки, \% \\
\hline \multirow{2}{*}{ Базовый } & 1-е занятие & 85 & 55 \\
\hline & 2-е занятие & 90 & 60 \\
\hline \multirow{4}{*}{ Ударный } & 1-е занятие & 95 & 75 \\
\hline & 2-е занятие & 100 & 85 \\
\hline & 3-е занятие & 100 & 90 \\
\hline & 4-е занятие & 100 & 90 \\
\hline \multirow{3}{*}{ Восстановительный } & 1-е занятие & 30 & 20 \\
\hline & 2-е занятие & 30 & 30 \\
\hline & 3-е занятие & 40 & 40 \\
\hline \multirow{4}{*}{$\begin{array}{c}\text { Контрольно-подготовитель- } \\
\text { ный }\end{array}$} & 1-е занятие & 80 & 50 \\
\hline & 2-е занятие & 85 & 55 \\
\hline & 3-е занятие & 90 & 60 \\
\hline & 4-е занятие & 90 & 75 \\
\hline \multirow{3}{*}{ Предсоревновательный } & 1-е занятие & 95 & 90 \\
\hline & 2-е занятие & 80 & 95 \\
\hline & 3-е занятие & 75 & 96 \\
\hline \multirow{3}{*}{ Восстановительный } & 1-е занятие & 30 & 30 \\
\hline & 2-е занятие & 40 & 30 \\
\hline & 3-е занятие & 40 & 40 \\
\hline \multirow{3}{*}{ Соревновательный } & 1-е занятие & 90 & 100 \\
\hline & 2-е занятие & 90 & 100 \\
\hline & 3-е занятие & 90 & 100 \\
\hline \multirow{4}{*}{ Восстановительный } & 1-е занятие & 30 & 20 \\
\hline & 2-е занятие & 30 & 20 \\
\hline & 3-е занятие & 40 & 30 \\
\hline & 4-е занятие & 50 & 30 \\
\hline
\end{tabular}


Основываясь на разработанных В. Ф. Пешковым научно-методических подходах к планированию восстановительных средств в спорте [1], наиболее эффективным нам представляется именно комплексное планирование педагогических, медико-биологических и психологических средств восстановления боксеров в соревновательном мезоцикле. Приоритеты этих средств могут меняться в зависимости от функционального состояния спортсменов. В данных восстановительных микроциклах, помимо планирования восстановительнопрофилактических средств педагогического, медико-биологического и психологического характера, планировались средства общей физической подготовки, характерные и нехарактерные для бокса, средства специальной физической и технической подготовки.

Длительное применение одного и того же средства восстановления избирательного воздействия уменьшает восстановительный эффект, так как организм адаптируется к средствам локального воздействия. К средствам глобального воздействия (парная баня, финская сауна, инфракрасная сауна в сочетании с водными процедурами, общий ручной массаж) адаптация организма происходит постепенно, и восстановительные эффекты сохраняются более длительное время [10]. В связи с этим использовались комплексы, а не отдельные восстановительные средства, которые дают бо́льший восстановительный эффект [3]. При применении восстановительных комплексов вначале применялись средства общего глобального воздействия, а затем - локального. При выборе восстановительных средств особое внимание уделялось индивидуальной переносимости тренировочных и соревновательных нагрузок. Для этой цели оценивали субъективные ощущения боксеров, а также объективные показатели контроля по частоте сердечных сокращений.

Эффективность разработанного планирования в соревновательном мезоцикле восстановительных микроциклов доказана экспериментально. При подготовке боксеров экспериментальной группы в соревновательный мезоцикл соревновательного периода были включены три восстановительных микроцикла: после ударного, предсоревновательного и соревновательного микроциклов. В контрольной группе был запланирован и реализован один восстановительный микроцикл после соревновательного микроцикла, который включал три дня, в течение которых проведено три занятия восстановительного характера и четыре дня пассивного отдыха. До и после соревновательного микроцикла было проведено тестирование, оценивающее функциональную подготовленность боксеров по показателям эффективности восстановительного периода в течение одной минуты после выполнения специфической нагрузки. В табл. 2 представлены результаты тестирования после эксперимента.

Таблица 2

Результаты оценки функииональной подготовленности боксеров экспериментальной

и контрольной групп после эксперимента

\begin{tabular}{|c|c|c|c|c|c|c|c|c|}
\hline \multirow{3}{*}{$\begin{array}{c}\text { Наблюдаемая } \\
\text { группа }\end{array}$} & \multicolumn{2}{|c|}{$\begin{array}{c}\text { Спурты на мешках } \\
\text { по } 10 \text { с, через каж- } \\
\text { дые } 10 \text { с отдыха } \\
\text { в течение } 1,5 \text { мин }\end{array}$} & \multicolumn{2}{|c|}{$\begin{array}{c}\text { Спурты на скакалке } \\
\text { по } 5 \text { с, через каждые } \\
10 \text { с отдыха в тече- } \\
\text { ние } 1,5 \text { мин }\end{array}$} & \multicolumn{2}{|c|}{$\begin{array}{c}\text { По заданию } \\
\text { «Бой с тенью» }\end{array}$} & \multicolumn{2}{|c|}{$\begin{array}{c}\text { Работа на мешке } \\
\text { по выбору спортсме- } \\
\text { на в высоком темпе }\end{array}$} \\
\hline & \multicolumn{8}{|c|}{ Частота сердечных сокращений, уд./мин } \\
\hline & $\begin{array}{c}\text { после } \\
\text { нагрузки }\end{array}$ & $\begin{array}{c}\text { через } 1 \text { мин } \\
\text { восстанов- } \\
\text { ления } \\
\end{array}$ & $\begin{array}{c}\text { после } \\
\text { нагрузки }\end{array}$ & $\begin{array}{c}\text { через } 1 \text { мин } \\
\text { восстанов- } \\
\text { ления } \\
\end{array}$ & $\begin{array}{c}\text { после } \\
\text { нагрузки }\end{array}$ & $\begin{array}{c}\text { через } 1 \text { мин } \\
\text { восстанов- } \\
\text { ления } \\
\end{array}$ & $\begin{array}{c}\text { после } \\
\text { нагрузки }\end{array}$ & \begin{tabular}{|c|} 
через 1 мин \\
восстанов- \\
ления \\
\end{tabular} \\
\hline Экспериментальная & $\begin{array}{c}179,8 \pm \\
\pm 7,4\end{array}$ & $\begin{array}{c}126,7 \pm \\
\pm 3,1\end{array}$ & $\begin{array}{c}170,0 \pm \\
\pm 5,6\end{array}$ & $\begin{array}{c}120,1 \pm \\
\pm 3,6\end{array}$ & $\begin{array}{c}167,8 \pm \\
\pm 7,2\end{array}$ & $\begin{array}{c}119,8 \pm \\
\pm 4,0\end{array}$ & $\begin{array}{c}173,1 \pm \\
\pm 6,9\end{array}$ & $\begin{array}{c}121,8 \pm \\
\pm 3,6\end{array}$ \\
\hline Контрольная & $\begin{array}{c}182,0 \pm \\
\pm 7,2\end{array}$ & $\begin{array}{c}147,7 \pm \\
\pm 3,3\end{array}$ & $\begin{array}{c}176,3 \pm \\
\pm 6,5\end{array}$ & $\begin{array}{c}145,1 \pm \\
\pm 3,1\end{array}$ & $\begin{array}{c}175,4 \pm \\
\pm 6,8\end{array}$ & $\begin{array}{c}141,1 \pm \\
\pm 3,7\end{array}$ & $\begin{array}{c}188,8 \pm \\
\pm 8,3\end{array}$ & $\begin{array}{c}154,5 \pm \\
\pm 3,2\end{array}$ \\
\hline
\end{tabular}


Тестами являлись упражнения на боксерских снарядах, скакалке, «бой с тенью» и работа по выбору спортсмена. Тесты выполнялись в максимальном темпе в течение 10 секунд с перерывами 10 секунд в течение 90 секунд.

Результаты тестирования показали, что боксеры экспериментальной группы благоприятнее переносят специфические скоростно-силовые нагрузки. Восстановление частоты сердечных сокращений (ЧСС) у них в границах критериев «очень хорошее» и «отличное», что свидетельствует об эффективных восстановительных реакциях и сохранении высокой функциональной подготовленности. В контрольной группе восстановление ЧСС характеризуется границами критериев «удовлетворительное» и «неудовлетворительное», что указывает на недостаточную функциональную подготовленность боксеров контрольной группы.

Разработанное планирование восстановительных микроциклов в соревновательном периоде боксеров, тренирующихся на этапе спортивной специализации, было внедрено в содержание темы «Планирование восстановительных средств в спорте» учебных дисциплин «Восстановительные средства в спорте», «Теория и методика восстановительных средств», преподаваемых на факультете физической культуры и спорта Томского государственного педагогического университета. Тестирование знаний по данной теме показало, что обучающиеся освоили знания в области планирования средств восстановления в спорте и, в частности, новый, включенный учебный материал о специфике планирования восстановительных микроциклов в структуре соревновательного мезоцикла соревновательного периода боксеров, тренирующихся на этапе спортивной специализации.

Таким образом, можно сделать следующие выводы:

1. Теоретически обоснованный, разработанный и апробированный в тренировочном процессе боксеров учебный материал по вопросу «Планирование восстановительных микроциклов в соревновательном периоде боксеров, тренирующихся на этапе спортивной специализации», внедрен в содержание учебной темы «Планирование восстановительных средств в спорте» дисциплин, преподаваемых на факультетах физической культуры и спорта.

2. Разработаный учебный материал включает следующее: планирование трех восстановительных микроциклов в соревновательном мезоцикле, комплексное применение восстановительных средств в структуре восстановительных микроциклов в различном процентном соотношении, в сочетании со средствами общей, специальной физической и технической подготовки, рациональное процентное соотношение средств педагогического, медико-биологического и психологического характера восстановления во всех трех восстановительных микроциклах в системе подготовки боксеров экспериментальной группы, тренирующихся на этапе спортивной специализации, обеспечивает более высокий уровень специальной функциональной подготовленности в конце соревновательного мезоцикла, завершившегося соревновательным и восстановительным микроциклами, по сравнению с функциональной подготовленностью боксеров контрольной группы, для которой традиционно планировался один восстановительный микроцикл в конце соревновательного периода и включает преимущественно дни пассивного отдыха.

\section{Список литературы}

1. Пешков В. Ф. Рабочая программа учебной дисциплины «Восстановительные средства в спорте» по направлению подготовки 44.03.05 «Педагогическое образование». Томск: ТГПУ, 2016. 10 с.

2. Пешков В. Ф. Рабочая программа учебной дисциплины «Теория и методика восстановительно-профилактических средств» по направлению подготовки 44.03.05 «Педагогическое образование». Томск: ТГПУ, 2016. 11 с.

3. Пешков В. Ф. Обоснование темы «Планирование восстановительных средств в спорте» дисциплины «Теория и методика восстановительных средств» // Вестн. Томского гос. ун-та. 2019. № 441. С. 213-219. 
4. Пешков В. Ф. Обоснование восстановительно-профилактической подготовки в структуре спортивной подготовки // Вестн. Томского гос. пед. ун-та (TSPU Bulletin). 2017. Вып. 1 (178). С. 136-142. DOI: 10.23951/1609-624X-2017-1-136-142.

5. Пешков В. Ф. Педагогическая система профрессиональной восстановительно-профилактической подготовки педагогов по физической культуре и спорту: дис. ... д-ра пед. наук. Томск, 2009. 333 с.

6. Пешков В. Ф. Восстановительные средства в профессиональной деятельности педагогов по физической культуре и спорту. Томск: Изд-во Том. ун-та, 2000. 196 с.

7. Волков В. М., Жилло Ж., Костюченков В. Н. Средства восстановления в спорте. Смоленск: Смядынь, 1994. 159 с.

8. Геселевич В. В. Восстановление в системе индивидуальной подготовки спортсменов высокого класса // Восстановление и повышение спортивной работоспособности: материалы Всерос. науч.-практ. конф. / под ред. Н. Д. Граевской. Малаховка: МОГИФК, 1992. С. 16-20.

9. Мирзоев О. М. Восстановительные средства в системе подготовки спортсменов. М.: ФиС; Спортакадемпресс, 2005. $211 \mathrm{c}$.

10. Платонов В. Н. Двигательные качества и физическая подготовка спортсменов. М.: Спорт, 2019. 656 с.

11. Акопян А. О. Современные подходы к скоростно-силовой подготовке единоборцев // Проблемы и перспективы развития фиизической культуры и спорта в XXI веке: сб. науч. трудов. Волгоград: ВГУ, 2004. С. 10-14.

12. Базеян А. М. Технико-тактическая подготовка боксеров-юниоров на основе учета показателей их соревновательной деятельности: автореф. дис. ... канд. пед. наук. М., 1990. 24 с.

13. Родионов В. И. Силовая подготовка боксера // Бокс: ежегодник. 2015. С. 17-22.

Пешков Владимир Федорович, доктор педагогических наук, профессор, заведующий кафедрой, Томский государственный педагогический университет (ул. Киевская, 60, Томск, Россия, 634061). E-mail: peshkov@sidmail.com

Григорян Артур Ваганович, магистрант, Томский государственный педагогический университет (ул. Киевская, 60, Томск, Россия, 634061).

Материал поступил в редакиию 20.11.2019.

DOI 10.23951/2307-6127-2020-1-154-161

\section{FORMATION OF KNOWLEDGE ON CONSTRUCTION OF RESTORATIVE MICRO-CYCLES IN COMPETITIVE PERIOD OF TRAINING CYCLE AMONG STUDENTS OF FACULTIES OF PHYSICAL TRAINING AND SPORTS}

\section{F. Peshkov, A. V. Grigoryan}

\section{Tomsk State Pedagogical University, Tomsk, Russian Federation}

The article presents the justification, development and results of testing of educational material on the topic "Planning of restorative means in sports" for academic disciplines of restorative and preventive orientation and disciplines on combat sports taught at universities and departments of physical training and sports. The justification of the content of the educational topic is based on scientific and methodological approaches to planning of restorative means in sports, theory and methodology of restorative and preventive means, theory and methodology of sports training. The variant of planning of restorative microcycles in the structure of competitive period of boxers training at the stage of sports specialization has been developed. The place of restorative micro-cycles in the structure of the competitive meso-cycle of boxers competitive period, percentage ratio of the volume of general physical and special physical training, technical training and the volume of application of the complex of pedagogical, medico-biological and psychological means of recovery for each of the planned restorative micro-cycles have been determined. The ratio of application of pedagogical, medico-biological and psychological means of recovery in three planned restorative micro-cycles is presented. The effectiveness of the developed planning option has been experimentally proved. 
Keywords: vocational training, competitive micro-cycle, competitive period, restorative micro-cycles, restorative means.

\section{References}

1. Peshkov V. F. Rabochaya programma uchebnoy distsypliny "Vosstanovitel'nyye sredstva v sporte" po napravleniyu podgotovki 44.03.05 "Pedagogocheskoye obrazovaniye" [Steering document on the academic discipline "Restorative Means in Sports" of the degree course 44.03.05 "Pedagogical Education"]. Tomsk, TSPU Publ., 2016. 10 p. (in Russian).

2. Peshkov V. F. Rabochaya programma uchebnoy distsypliny "Teoriya i metodika vosstanovitel'no-profilacticheskikh sredstv" po napravleniyu podgotovki 44.03.05 "Pedagogocheskoye obrazovaniye" [Steering document on the academic discipline "Theory and Methodology of Restorative and Preventive Means" of the degree course 44.03.05 "Pedagogical Education"]. Tomsk, TSPU Publ., 2016. 11 p. (in Russian).

3. Peshkov V. F. Obosnovaniye temy "Planirovaniye vosstanovitel'nykh sredstv" distsypliny "Teoriya i metodika vosstanovitel'noprofilakticheskikh sredstv" [Justification of the Topic "Planning of Restorative Means" in the academic discipline "Theory and Methodology of Restorative and Preventive Means"]. Vestnik Tomskogo gosudarstvennogo universiteta - Tomsk State University Journal, 2019, no. 441, pp. 213-219 (in Russian).

4. Peshkov V. F. Obosnovaniye vosstanovitel'no-profilakticheskoy podgotovki v structure sportivnoy podgotovki [Justification of restorative and preventive means in the structure of sports training]. Vestnik Tomskogo gosudarstvennogo pedagogicheskogo universiteta - TSPU Bulletin, 2017, vol. 1 (178), pp. 136-142 (in Russian). DOl: 10.23951/1609-624X-2017-1-136-142.

5. Peshkov V. F. Pedagogicheskaya sistema professional'noy vosstanovitel'no-profilacticheskoy podgotovki pedagogov po fizicheskoy kul'ture i sportu. Dis. dokt. ped. nauk [Pedagogical system of professional restorative and preventive training of teachers of physical training and sports. Diss. of doct. ped. sci.]. Tomsk, 2009. 333 p. (in Russian).

6. Peshkov V. F. Vosstanovitel'nyye sredstva v professional'noy deyatel'nosti pedagogov po fizicheskoy kul'ture $i$ sportu [Restorative means in work of teachers of physical training and sports]. Tomsk, Tomsk University Publ., 2000. 196 p. (in Russian).

7. Volkov V. M., Zhillo Zh., Kostyuchenkov V. N. Sredstva vosstanovleniya v sporte [Restorative means in sports]. Smolensk, Smyadyn' Publ., 1994. 159 p. (in Russian).

8. Geselevich V. V. Vosstanovleniye v sisteme individual'noy podgotovki sportsmenov vysokogo klassa [Recovery in the system of individual training of competitive sportsmen] Vosstanovleniye i povysheniye sportivnoy rabotosposobnosti: materialy Vseros. nauch.-prakt. konf. Pod red. N. D. Grayevskoy [Recovery and enhancement of performance efficiency: proceedings of the Russian national scientific and practical conference. Ed. N. D. Grayevskaya]. Malakhovka, MOGIFK Publ., 1992. Pp. 16-20 (in Russian).

9. Mirzoyev O. M. Vosstanovitel'nyye sredstva v sisteme podgotovki sportsmenov [Restorative means in the system of sportsmen training]. Moscow, FiS, Sportakadempress Publ., 2005. 211 p. (in Russian).

10. Platonov V. N. Dvigatel'nyye kachestva i fizicheskaya podgotovka sportsmenov [Qualities of movement and physical training of sportsmen]. Moscow, Sport Publ., 2019. 656 p. (in Russian).

11. Akopyan A. O. Sovremennyye podkhody k skorostno-silovoy podgotovke edinobortsev [Modern approaches to the strengthbuilding training of combatants]. Problemy i perspectivy razvitiya fizicheskoy kul'tury i sporta v XXI veke: sbornik nauchnych trudov [Problems and prospective of development of physical training and sports in the $21^{1 \mathrm{t}}$ century: proceedings]. Volgograd, VSU Publ., 2004. Pp. 10-14 (in Russian).

12. Bazeyan A. M. Tekhniko-prakticheskaya podgotovka bokserov-yuniorov na osnove ucheta pokazateley ikh sorevnovatel'noy deyatel'nosti. Avtoref. dis. kand. ped. nauk [Technical and tactical training of junior boxers in accordance with their competitive results. Abstract of thesis of cand. ped. sci.]. Moscow, 1990. 24 p. (in Russian).

13. Rodionov V. I. Silovaya podgotovka boksera [Strength-building training of a boxer]. Boks: yezhegodnik [Boxing: annuary]. Moscow, Fizkul'tura i sport Publ., 2015. Pp. 17-22 (in Russian).

Peshkov V. F., Tomsk State Pedagogical University (ul. Kiyevskaya, 60, Tomsk, Russian Federation, 634061).E-mail:peshkov@sidmail.com

Grigoryan A. V., Tomsk State Pedagogical University (ul. Kiyevskaya, 60, Tomsk, Russian Federation, 634061). 